\title{
Rapid detection of Candida parapsilosis contamination in the infusion fluid
}

\author{
Shigeharu Oie*1,2, Kyoji Kouda ${ }^{2}$, Hiroyuki Furukawa ${ }^{2}$, Akira Kamiya $^{3}$ \\ ${ }^{1}$ Laboratory of Hospital Hygiene and Infection Control, Japan \\ ${ }^{2}$ Yamaguchi University Hospital, Japan \\ ${ }^{3}$ Sanyo-onoda City University, Japan
}

Received: April 25, 2018

DOI: $10.5430 / \mathrm{cns} . v 6 \mathrm{n} 4 \mathrm{p} 80$
Accepted: June 21, 2018

Online Published: June 28, 2018

\begin{abstract}
We encountered a case of microbial contamination of infusion fluid detected based on the discoloration of an inline filter (membrane filter) in the main route. A cause of this contamination may be the use of an extension tube connected to the main route for more than a month. In the infusion fluid above the inline filter (on the high calorie end), $2.4 \times 10^{5}$ colony forming units (cfu)/ml of Candida parapsilosis was detected. "Adenosine triphosphate (ATP) + adenosine monophosphate (AMP)" was determined in addition. We conclude that microbial contamination of this infusion fluid can be rapidly estimated by measuring the amounts of "ATP + AMP".
\end{abstract}

Key Words: Contamination, Infusion, Fentanyl, Candida parapsilosis, ATP

\section{INTRODUCTION}

Microbial contamination during injections leads to serious consequences such as sepsis. ${ }^{[1-8]}$ However, due to difficulties of visually confirming the contamination by the naked eye and added time required to plate and grow the contaminating species, the infusion fluid does not currently receive rigorous testing as a possible source of microbes causing sepsis in a patient. In clinical practice, we encountered a case in which microbial contamination of an injection was detected based on the discoloration of an inline filter (membrane filter) of the central venous line. Although discoloration of the filter was noticed in the filter, the contamination of the filter was not initially suspected as the cause of the contamination. Therefore, a method for rapidly detecting the presence of microbial contamination is urgently required. In this study, the availability of "adenosine triphosphate (ATP) + adenosine monophosphate (AMP)" measurement as the rapid estimation of microbial contamination in the infusion fluid was evaluated.

\section{MATERIAls AND METHODS}

\subsection{Background}

The Department of Pharmacy received an inquiry from a nurse in charge of a 62-year-old male receiving intravenous hyperalimentation (IVH) in the inpatients' hospital ward after surgery for esophageal cancer. The nurse had noticed that the inline filter of the drip infusion set had become brown in color. The nurse initially had suspected drug incompatibility. A high calorie infusion fluid (Elneopa ${ }^{\circledR}$ No.1, Terumo Co., Japan) was being administered through the main route while fentanyl (Janssen Pharmaceutical Japan Co., Japan) was being administered from a side tube connected to the

*Correspondence: Shigeharu Oie; Email: oie @ frontier-u.jp; Address: 4-2-15 Astopia, Ube 755-0152, Japan. 
main route (see Figure 1). Both the high calorie infusion fluid bag and the fentanyl injection together with the syringe were replaced at 24-hour intervals.

\subsection{Investigation of microbial contamination and mea- surement of "ATP + AMP"}

The residual fluid in the main route was diluted with normal sterile saline. Pipettes were used to transfer $1 \mathrm{ml}$ of undiluted or diluted samples to grow any bacteria on trypticase soy agar containing blood and to grow any fungi on Sabouraud dextrose agar. The plates were streaked with a glass "hockey stick" and incubated at $35^{\circ} \mathrm{C}$ for $24-72 \mathrm{~h}$. Colonies were counted, and organisms were identified by Gram staining, morphological examination, the oxidation fermentation test, cytochrome-oxidase test, and the API system (bio-Mérieux SA, L'Etoile, France).

For the measurement of "ATP + AMP" (relative light units: RLU), sampling was performed using LuciPac ${ }^{T M}$ Pen-AQUA (Kikkoman Biochemifa Co., Japan), and RLU was measured using Lumitester ${ }^{T M}$ PD-20 (Kikkoman Biochemifa Co.).
The inner walls of the main route and extension tube were observed using a field emission scanning electron microscope (JSM-7000F, JEOL Co., Japan) after gold evaporation at an accelerating voltage of $5 \mathrm{kV}$.

\section{RESULTS}

Figure 1 shows viable counts of $C$. parapsilosis and the amounts of "ATP + AMP" (RLU). This microorganism was not detected in the fentanyl injection in the syringe, inside the high calorie infusion fluid bag, in the high calorie infusion fluid in the drip tube connected to the bag, or in the fluid in the main route from the inline filter to the patient. The RLU was 0-93. However, in the other areas, this microorganism was detected, and the RLU was 2,200-2,745. High RLU strongly correlated with the high colony forming units (cfu) $\left(2.2-2.4 \times 10^{5}\right)$.

Figure 2 shows a micrograph $(\times 4,000)$ of the inner wall of the extension tube. Attachment of a large amount of C. parapsilosis was observed on the inner wall of the extension tube. However, $C$. parapsilosis was not confirmed on the inner wall of the main route.

\section{Distal to patient}

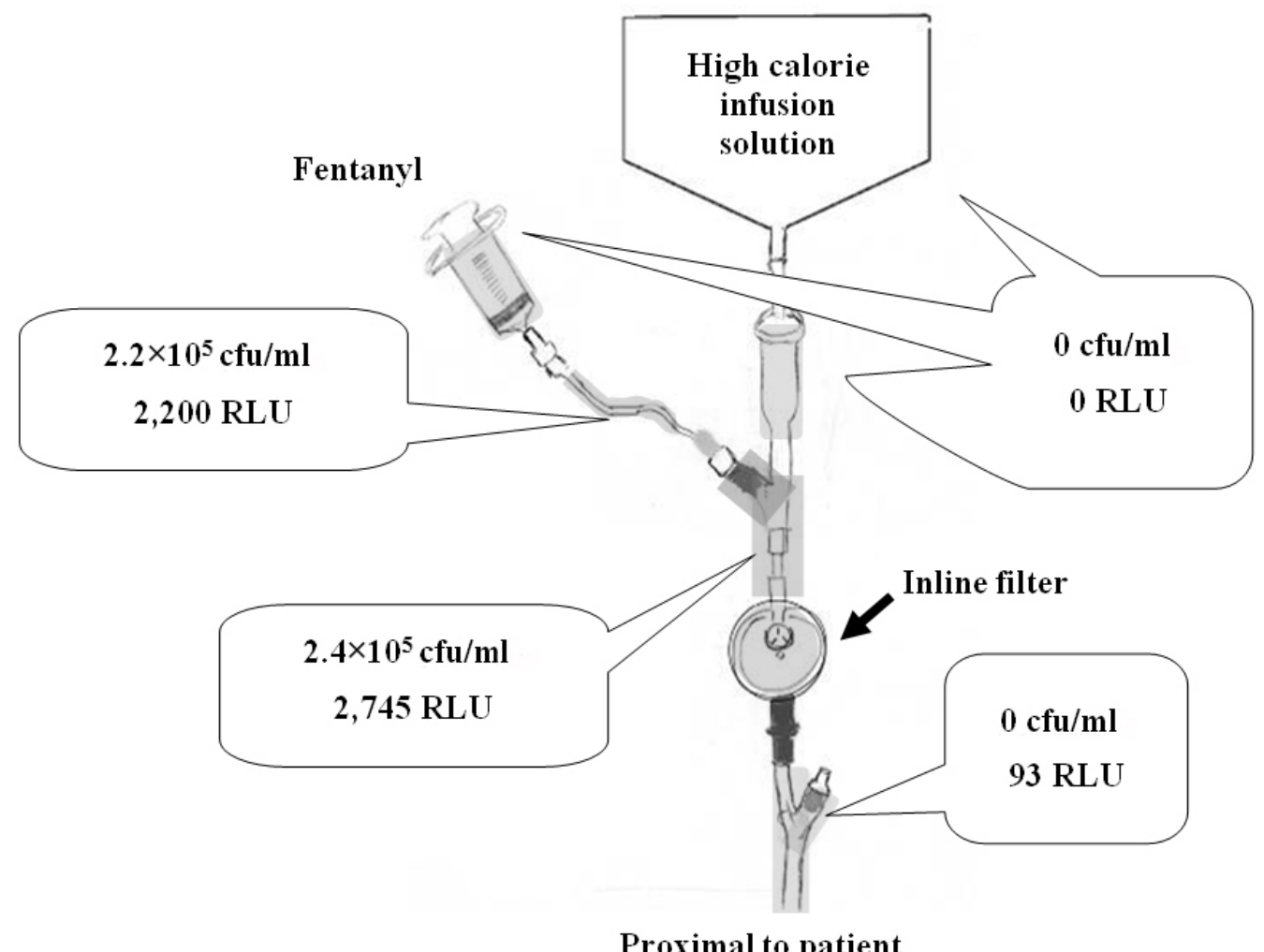

Figure 1. C. parapsilosis count and "ATP + AMP" (RLU) in a case of infusion fluid contamination 


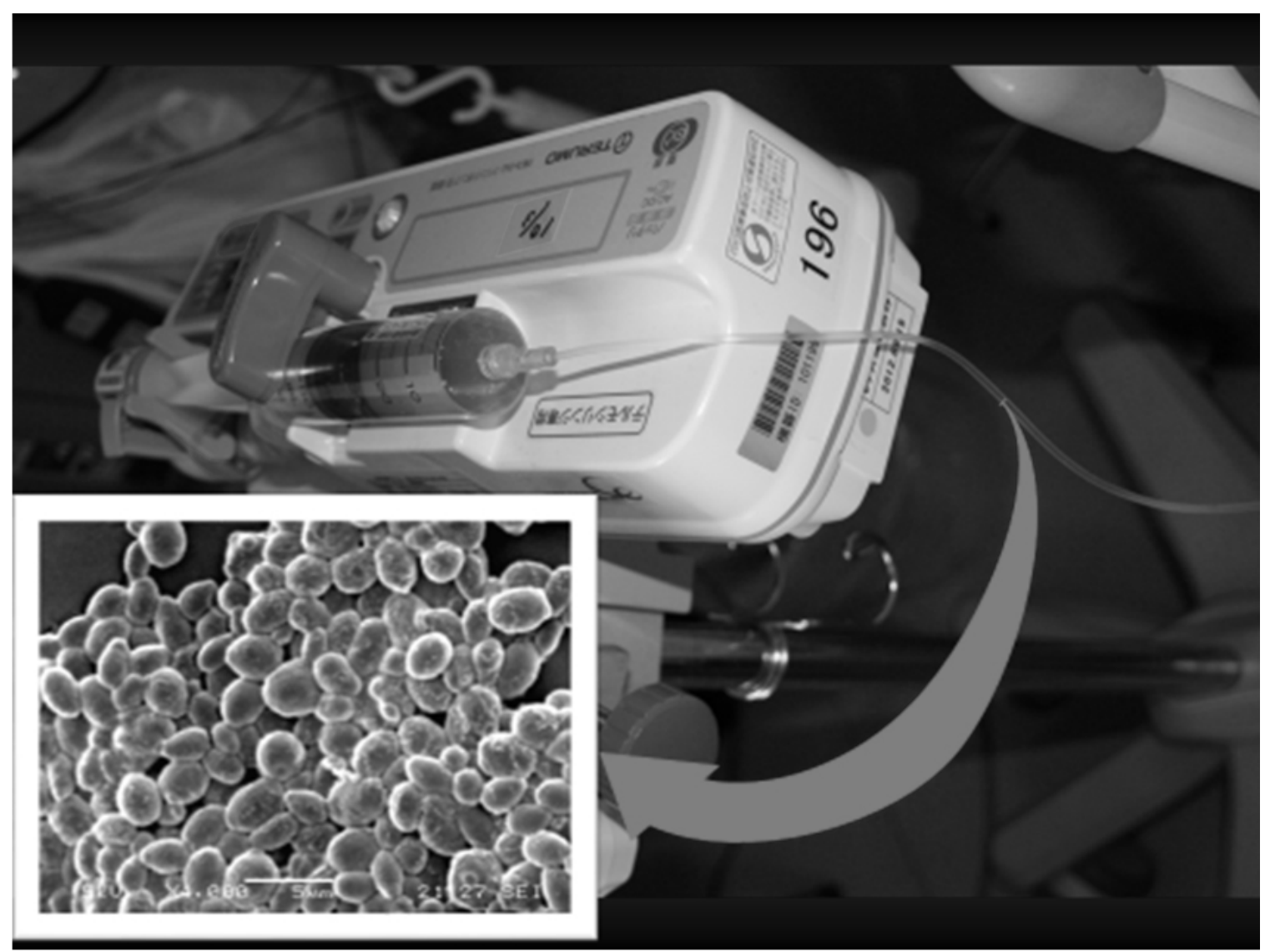

Figure 2. An electron micrograph $(\times 4,000)$ of the inner wall of the extension tube

\section{Discussion}

The observation of microbial contamination in medical drugs by the naked eye is rare. ${ }^{[9]}$ Since many drugs do not have adequate nutrients for microorganisms, their microbial contamination at a level allowing visual confirmation (about $10^{7} \mathrm{cfu} / \mathrm{ml}$ for bacteria and about $10^{6} \mathrm{cfu} / \mathrm{ml}$ for yeast-like fungi) does not normally occur. However, in this case, since an inline filter was used in the main route of high calorie infusion fluid, microbial contamination was detected based on the color of the inline filter. C. parapsilosis is normally white, but may have changed to light brown after turning yellow due to vitamin $\mathrm{C}$ as a component of the high calorie infusion fluid.

Microscopy of the inner wall of the used extension tube revealed attachment of a large amount of $C$. parapsilosis to the inner wall of the extension tube used for fentanyl injection administration (see Figure 2). Fentanyl injections have been reported to be susceptible to microbial contamination. ${ }^{[10-14]}$ In this case, colonization on the inner wall of the extension tube during fentanyl administration was considered. We hypothesize that the contamination may have occurred by not exchanging the extension tube for more than 30 days. Although the hospital was required to exchange the extension tubes and main route twice every week, ${ }^{[15]}$ the extension tube was not exchanged due to exemption warranted by the protocol for having opioid fentanyl in the extension tube. C. parapsilosis is part of normal skin flora ${ }^{[16]}$ and therefore it is possible that the extension tube was contaminated due to improper handling.

ATP measurement for the rapid estimation of microbial contamination has been evaluated in in vitro studies. ${ }^{[11,17,18]}$ However, ATP is known to be degraded to ADP and subsequently to AMP by the metabolism. Moreover, previous study showed that AMP may predominate over ATP according to microbial species and cell conditions. ${ }^{[19]}$ Therefore, measuring ATP and its metabolites, rather than ATP alone, seems to be useful to detect microbes and contaminants. Since the rapid "ATP + AMP" monitoring test kit is commercially available, "ATP + AMP" was measured in order to confirm the microbial contamination. Basically, this test kit is not for the specific detection of microorganism because the "ATP + AMP" increase can also be caused by organic substances except for bacteria, such as body fluid. However, as shown in Figure 1, the high correlation between "ATP + AMP" and cfu was observed, and bacteria in the infusion fluid could be monitored using the "ATP + AMP" test. Once 
a slight contamination is happened, bacteria seem to grow and produce the large amount of "ATP + AMP". The results of those studies suggest that "ATP + AMP" measurement is applicable and useful in the clinical setting. In the future, we intend to further investigate the microbial contamination during injections with the aim to establishing a rapid detection method of microbial contamination.

\section{Conclusions}

"ATP + AMP" measurement may be applicable and useful for rapid detection of microbial contamination of infusion systems in the clinical setting.

\section{CONFLICTS OF INTEREST DisClosure}

The authors declare they have no conflicts of interest.

\section{REFERENCES}

[1] Elamin S, Abu-Aisha H. Prevention of hepatitis B virus and hepatitis $\mathrm{C}$ virus transmission in hemodialysis centers: review of current international recommendations. Arab J Nephrol Transplant. 2011 Jan; 4(1): 35-47. PMid: 21469594. https ://doi.org/10.4314/ajnt .$v 4 i 1.63154$

[2] Grohskopf LA, Roth VR, Feikin DR, et al. Serratia liquefaciens bloodstream infections from contamination of epoetin alfa at a hemodialysis center. N Engl J Med. 2001 May; 344(20): 14917. PMid: 11357151. https://doi.org/10.1056/NEJM200105 173442001

[3] Muller AE, Huisman I, Roos PJ, et al. Outbreak of severe sepsis due to contaminated propofol: lessons to learn. J Hosp Infect. 2010 Nov; 76(3): 225-30. PMid: 20692067. https://doi.org/10.1016/j. jhin.2010.06.003

[4] Ganeswire R, Thong KL, Puthucheary SD. Nosocomial outbreak of Enterobacter gergoviae bacteraemia in a neonatal intensive care unit. J Hosp Infect. 2003 Apr; 53(4): 292-6. PMid: 12660126. https://doi.org/10.1053/jhin.2002.1371

[5] De Smet B, Veng C, Kruy L, et al. Outbreak of Burkholderia cepacia bloodstream infections traced to the use of ringer lactate solution as multiple-dose vial for catheter flushing, Phnom Penh, Cambodia. Clin Microbiol Infect. 2013 Sep; 19(9): 832-7. PMid: 23173820. https://doi.org/10.1111/1469-0691.12047

[6] Germain JM, Carbonne A, Thiers V, et al. Patient-to-patient transmission of hepatitis $\mathrm{C}$ virus through the use of multidose vials during general anesthesia. Infect Control Hosp Epidemiol. 2005 Sep; 26(9): 789-92. PMid: 16209386. https://doi.org/10.1086/502618

[7] Behrens-Muller B, Conway J, Yoder J, et al. Investigation and control of an outbreak of Achromobacter xylosoxidans bacteremia. Infect Control Hosp Epidemiol. 2012 Feb; 33(2): 180-4. PMid: 22227988. https://doi.org/10.1086/663710

[8] Ersoz G, Uguz M, Aslan G, et al. Outbreak of meningitis due to Serratia marcescens after spinal anaesthesia. J Hosp Infect. 2014 Jun; 87(2): 122-5. PMid: 24814159. https://doi.org/10.101 $6 / j \cdot j h i n .2014 .03 .004$

[9] Oie S, Kamiya A. A case of microbial contamination of enteral feeding solution. Chemotherapy(Tokyo). 1992; 40: 743-6.

[10] Chiang PC, Wu TL, Kuo AJ, et al. Outbreak of Serratia marcescens postsurgical bloodstream infection due to contaminated intravenous pain control fluids. Int J Infect Dis. 2013 Sep; 17(9): e718-22. PMid: 23558318. https://doi.org/10.1016/j.ijid.2013.02.012
[11] Maragakis LL, Chaiwarith R, Srinivasan A, et al. Sphingomonas paucimobilis bloodstream infections associated with contaminated intravenous fentanyl. Emerg Infect Dis. 2009 Jan; 15(1): 12-8. PMid: 19116043. https://doi.org/10.3201/eid1501.081054

[12] Moehring RW, Lewis SS, Isaacs PJ, et al. Outbreak of bacteremia due to Burkholderia contaminans linked to intravenous fentanyl from an institutional compounding pharmacy. JAMA Intern Med. 2014 Apr; 174(4): 606-12. PMid: 24493147. https://doi.org/10.1 001/jamainternmed. 2013.13768

[13] Anderson RL, Highsmith AK, Holland BW. Comparison of the standard pour plate procedure and the ATP and Limulus amebocyte lysate procedures for the detection of microbial contamination in intravenous fluids. J Clin Microbiol. 1986 Mar; 23(3): 465-8. PMid: 3514657.

[14] Ostrowsky BE, Whitener C, Bredenberg HK, et al. Serratia marcescens bacteremia traced to an infused narcotic. $\mathrm{N}$ Engl $\mathrm{J}$ Med. 2002 May 16; 346(20): 1529-37. PMid: 12015392. https: //doi.org/10.1056/NEJMoa012370

[15] O'Grady NP, Alexander M, Burns LA, et al. Healthcare Infection Control Practices Advisory Committee (HICPAC) (Appendix 1). Summary of recommendations: Guidelines for the Prevention of Intravascular Catheter-related Infections. Clin Infect Dis. 2011 May; 52(9): 1087-99. PMid: 21467014. https://doi.org/10.1093/ cid/cir138

[16] Saiman L, Ludington E, Dawson JD, et al. National Epidemiology of Mycoses Study Group. Risk factors for Candida species colonization of neonatal intensive care unit patients. Pediatr Infect Dis J. 2001 Dec; 20(12): 1119-24. PMid: 11740316. https: //doi.org/10.1097/00006454-200112000-00005

[17] Griffith CJ, Cooper RA, Gilmore J, et al. An evaluation of hospital cleaning regimes and standards. J Hosp Infect. 2000 May; 45(1): 19-28. PMid: 10833340. https://doi.org/10.1053/jhin.199 9.0717

[18] Gibbs SG, Sayles H, Chaika O, et al. Evaluation of the relationship between ATP bioluminescence assay and the presence of organisms associated with healthcare-associated infections. Healthcare Infect. 2014; 19: 101-7. https://doi.org/10.1071/HI14010

[19] Sakakibara T, Murakami S, Imai K. Enumeration of bacterial cell numbers by amplified firefly bioluminescence without cultivation. Anal Biochem. 2003 Jan; 312(1): 48-56. https://doi .org/10.1 016/S0003-2697(02) 00427-X 